\title{
A POSSIBLE ORIGIN FOR THE MASS-INDEPENDENT ISOTOPIC FRACTIONATION: IMPLICATION FOR COSMOCHEMISTRY
}

\section{FRANÇOIS ROBERT}

CNRS/Museum National Histoire Naturelle

Presenting Author: francois.robert@mnhn.fr

Using the experimental results obtained for oxygen isotopes during the synthesis of ozone ${ }^{l}$, we have proposed a theoretical interpretation of the mass independent isotopic fractionation effect $^{2}$ (MIF). I will review its consequences for laboratory experiments.

Theoretical. A and B, 2 isotopes of the same element and M a chemical bond. The atom A resulting from photodissociation of $\mathrm{MA}$ reacts with its parent molecule $(\mathrm{A}+\mathrm{MA}$ or $\mathrm{A}+\mathrm{MB})$. An isotopic exchange takes place during this reaction as $A+M B \cap[A M B]^{*} \mathbb{R} B+M A$. If a fraction of the the activated complex $[\mathrm{AMB}]^{*}$ formed by this exchange reaction is involved in a chemical reaction, the chemical products should exhibit the MIF effect. This effect is caused by the fact that it is not possible to mathematically separate the exchange and the non-exchange processes when the complex is formed by the same isotopes (so called indistinguishable as [AMA $]^{*}$ ).

Experimental ${ }^{3}$ : The vapor pressure of liquids $\left(\mathrm{TiCl}_{4}\right.$ or $\mathrm{MgCl}_{2}$ in hydrocarbons) carried by $\mathrm{N}_{2}$ or $\mathrm{N}_{2} \mathrm{O}$ or $\mathrm{CO}_{2}$ gas flow at $\approx 1$ mbar, are submitted to a microwave discharge. Grains condensed in the so-formed plasma are deposited on silicon wafers ( $Æ » 1$ $\mathrm{mm}$ ) on top of organic films (thickness 10-100 nm).

Analytical: Isotopic compositions were measured using NanoSIMS. In grains, the variations in $\mathrm{Ti}, \mathrm{Mg}$ or $\mathrm{O}$ exceed $1000 \%$ (expressed in the usual $d$ units per mil). As suggested by Marcus ${ }^{4}$, the surface of a growing grain acts as a concentrator and enhances the rate of isotopic exchange compared to gas phase reactions. A similar effect may have occurred in the protosolar nebula during high temperature oxidation reactions of atoms.

References: [1] Thiemens M.H. \& Heidenreich J.E., (1983) Science, 219, 1073-1075. [2] Reinhardt P. and Robert F. (2018) J. Chem. Phys. 513, 287-294. [3]. Robert et al., Nat. Astron. (2020), 1-7 DOI: org/10.1038/s41550-020-1043-1.[4] Marcus R.A., (2004) J. Chem. Phys. 121, 8201-8211. 